\title{
APLICAÇÃO DE EXTRATO CAROTENOÍDICO NATURAL NA FORMULAÇÃO DE MASSA ALIMENTÍCIA FRESCA
}

Sara Albino Antunes Valcareggi ${ }^{1}$

Natália Mezzomo ${ }^{2}$

Sandra Regina Salvador Ferreira ${ }^{3}$

Haiko Hense $^{4}$

\section{Resumo}

Massas alimentícias são pigmentadas, principalmente, $\operatorname{com} \beta$-caroteno sintético. A adição de pigmentos provindos do aproveitamento de resíduos da indústria alimentícia pode agregar valor ao produto e diminuir problemas com descartes de resíduos. Sendo assim, o objetivo deste estudo foi determinar fatores físico-químicos e avaliar a aceitabilidade da massa alimentícia fresca com a adição de diferentes concentrações de extrato carotenoídico proveniente do resíduo de processamento de camarão rosa (P. brasiliensis e P. paulensis). Três diferentes formulações de massa alimentícia fresca foram preparadas, uma amostra controle e duas com adição de extrato carotenoídico (0,9\% e 3,1\% de extrato 10\%), proveniente do resíduo de processamento de camarão rosa. $\mathrm{O}$ extrato foi adicionado às formulações com a intenção de incrementar a coloração das massas alimentícias. Análises físico-químicas (umidade e voláteis, testes de cozimento e cor) foram realizadas, a fim de avaliar a qualidade das massas elaboradas. As formulações com adição do extrato diferiram significativamente em relação à coloração da amostra. A formulação II (3,1\% de extrato natural 10\%) promoveu os melhores resultados sensoriais, com um índice de 6,5 de aceitação global e de intenção de compra de 81,82\%.

Palavras-chave: Resíduo de camarão. Intenção de compra. Aceitação global.

Corante alimentício.

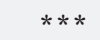

1 Mestre, e-mail: saraantunes@ outlook.com

2 Doutor, e-mail: natimezzomo@ gmail.com

3 Doutor, e-mail: s.ferreira@ufsc.br

4 Doutor, e-mail: haiko.hense@ufsc. br 


\section{INTRODUÇÃO}

O camarão ocupa lugar de evidência na economia pesqueira mundial. Quando industrializado, ele normalmente gera como resíduo o cefalotórax e o exoesqueleto, que juntos chegam a compreender $70 \%$ do peso da matéria-prima (SIMPSON; HAARD, 1985). Uma possível alternativa para agregar valor a este material é a sua utilização para extração de pigmentos carotenoides, devido ao grande potencial de aplicação destes compostos em diversas áreas.

A astaxantina é o principal pigmento encontrado em animais aquáticos, tais como lagosta, siri e camarão (HU et al., 2006; MEZZOMO et al.,2011).Este pigmento apresenta importante atividade biológica, principalmente protegendo sistemas contra radicais livres, peroxidação lipídica, oxidação de ácidos graxos poli-insaturados essenciais, efeitos da luz UV, entre outros (HU et al., 2006).

A astaxantina de origem natural tem sido avaliada como fonte de carotenoides em alguns estudos, nos quais os autores incorporam organismos como o camarão Penaeus japonicus (CHOUBERT; LUQUEST, 1983), Copépodos, C. Finmarchicus, krill, Euphasiasp. (LAMBERSTEN;BREKKAN,1971) na dieta de animais, como peixes e frangos, a fim de que estas possam produzir pigmentação rosada da carne em diferentes graus de intensidade, variando a coloração conforme a concentração de pigmentos nesses organismos.

Massa alimentícia fresca é o produto não fermentado, apresentado sob várias formas, recheado ou não, obtido pelo empasto, amassamento mecânico da mistura de farinha de trigo ou sêmola de trigo durum, e/ou farinha de outros vegetais, adicionado ou não de outros ingredientes e acompanhado ou não de temperos e/ou complementos, isoladamente ou adicionados diretamente à massa, podendo ou não ser submetido a um processo de secagem parcial de forma que o produto final apresente umidade máxima de 35,0\% (BRASIL, 2000).

No ano de 2014, o consumo no Brasil de massa alimentícia fresca foi de 51 mil toneladas, com um grande potencial de expansão deste mercado para os anos seguintes, pois estes produtos possuem alta aceitação dos consumidores e constituem uma importante fonte de carboidratos na alimentação humana (ABIMAPI,2016).

Atualmente MASSAS

ALIMENTÍCIAS SÃO

PIGMENTADAS

MAJORITARIAMENTE COM

$\beta$-CAROTENO SINTÉTICO (ITEP,

1985; BOROSKI ET AL., 2011).

A adição de pigmentos provenientes de fontes naturais,como resíduos daindústria alimentícia, pode agregarvalor a esses produtos e diminuir os problemas relacionados ao descarte de resíduos. Desta forma, o objetivo deste estudo foi avaliar a aceitabilidade e fatores físico-químicos da massa alimentícia fresca com a adição de diferentes concentrações de extrato carotenoídico proveniente do resíduo de processamento de camarão rosa (P. brasiliensis e $P$. paulensis). 


\section{MATERIAL E MÉTODOS}

\subsection{Obtenção dos extratos}

\section{carotenoídicos}

O resíduo de processamento do camarão, composto pela cabeça e encefalotórax do crustáceo, foi obtido na Peixaria Nelson Santos (Florianópolis/SC, Brasil), localizado no mercado público municipal. A matéria-prima foi pré-tratada com coç̧ão, secagem e moagem, de acordo com resultados de Mezzomo et al. (2011).

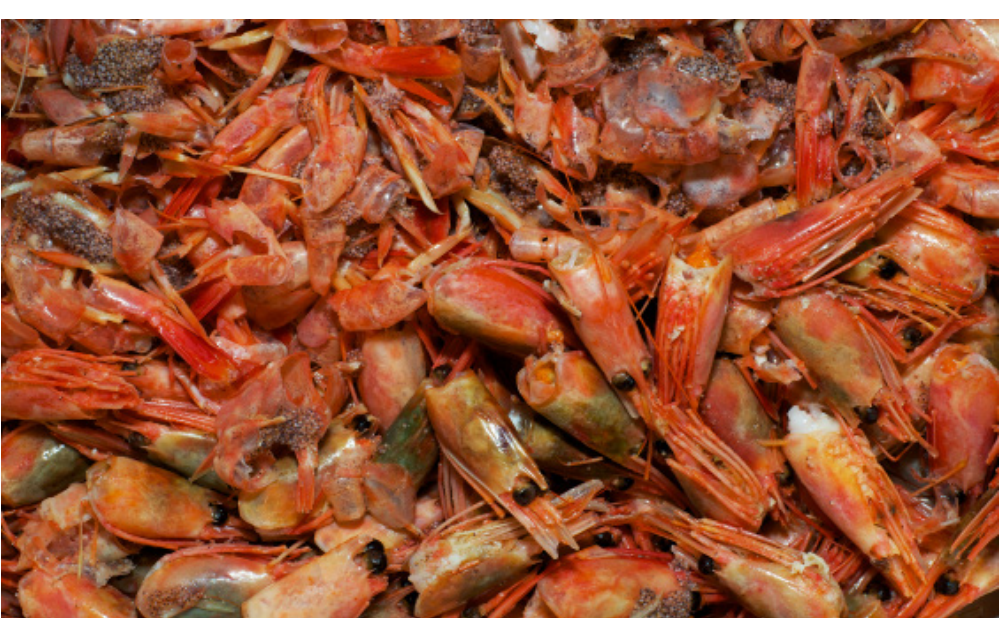

Para a extração, utilizou-se o método de maceração com acetona, de acordo com procedimento descrito por Mezzomo et al. (2011).

O método consiste na transferência de $25 \mathrm{~g}$ de matéria-prima pré-tratada em $100 \mathrm{ml}$ de acetona, mantendo o sistema em contato durante 5 dias sob temperatura ambiente e agitação manual a cada 24 horas. Ao final dos 5 dias, a mistura extrato mais solvente foi separada da matriz sólida através de filtração com celulose.

O filtrado foi concentrado em evaporador rotativo (FISATOM 802, São Paulo/SP, Brasil) com redução de pressão (NT 613, Nova Técnica, Piracicaba/SP, Brasil), a fim de eliminar o solvente orgânico. Os extratos crus obtidos foram armazenados a $-18^{\circ} \mathrm{C}$ em proteção de luz e atmosfera de nitrogênio até a formulação das massas.

O extrato bruto foi diluído em água destilada, a fim de se obter a concentração de 10\% (m/v), originando então a matéria-prima corante deste estudo (extrato do resíduo de camarão - ERC 10\%), sendo que a solução foi mantida sobre refrigeração até sua aplicação no alimento.

\subsection{Elaboração da massa alimentícia}

A elaboração da massa alimentícia fresca foi realizada conforme os padrões de qualidade estipulados pela ANVISA,na RDC no93, de 31 de outubro de 2000, que aprova o Regulamento técnico para fixação de identidade e qualidade de massa alimentícia ou macarrão e padrões de qualidade para a produção de alimentos. A Tabela 1 apresenta a porcentagem dos ingredientes utilizados na produção de massa alimentícia. 
Tabela 1: Formulações, porcentagem de ingredientes para a produção de massa alimentícia, utilizadas para os testes sensoriais e físico-químicos

\begin{tabular}{l|c|c|c|c|c|c}
\hline & \begin{tabular}{l}
\multicolumn{7}{c}{ Ingredientes (\%) } \\
Farinha detrigo \\
especial
\end{tabular} & Ovos & Água & ERC 10\% & Pasta de alho & Sal \\
\hline Controle & 61,8 & 30,9 & 3,1 & - & 3,7 & 0,5 \\
\hline Formulação I & 61,8 & 30,9 & 2,2 & 0,9 & 3,7 & 0,5 \\
\hline Formulação II & 61,8 & 30,9 & - & 3,1 & 3,7 & 0,5 \\
\hline
\end{tabular}

-: ingrediente não acrescentado à respectiva formulação

Fonte: Dos autores (2016)

Foramutilizados nas formulações:farinha de trigo (Triticum aestivum) Tipo 1 enriquecida com ferro e ácido fólico (NITA alimentos, Santos/ $\mathrm{SP}, \mathrm{Brasil}$ ); ovos frescos de granja (FRIOLAR, Araquari/SC, Brasil); água destilada; pasta de alho (KENKO, São Paulo/SP, Brasil); sal de cozinha iodado.

A medição dos ingredientes foi realizada em balança analítica (AY220, SHIMADZU, São Paulo/SP,Brasil).Logo após, foram misturados manualmente o ovo, a pasta de alho, o sal, a água e/ou o extrato do resíduo de processamento do camarão, de acordo com cada formulação requerida. Em seguida, a mistura de cada formulação foi acrescentada à farinha de trigo e misturado manualmente, com velocidade e tempos constantes entre todas as formulações.

O amassamento do composto alimentício foi realizado manualmente, até a massa se tornar firme, em tempo pré-determinado de aproximadamente 8 minutos.

A moldagem ou trefilação e o corte tipo talharim foram realizados conforme a descrição do fabricante, em equipamento de pequena escala usado para fabricação de massa alimentícia caseira (MALTA, Caxias do Sul/RS, Brasil).

Logo após o corte, as massas alimentícias foram polvilhadas com farinha de trigo, montadas em forma de "ninho" e submetidas à secagem em temperatura ambiente por 4 horas.

\subsection{Análises físico-químicas}

\subsubsection{Teor de umidade e voláteis}

O conteúdo de umidade e voláteis nas massas alimentícias foi determinado em duplicata, segundo a metodologia descrita pelo IAL (2008). A amostra correspondente a $5 \mathrm{~g}$ de massa alimentícia crua foi acondicionada em cápsulas de alumínio, aquecidas em estufa (E.L. 003, Odontobrás, Ribeirão Preto/SP, Brasil) a $105^{\circ} \mathrm{C}$ por $3 \mathrm{~h}$, resfriadas em dessecador até temperatura ambiente e pesadas. Repetiram-se estas operações de aquecimento e resfriamento até se obter peso constante. $\mathrm{O}$ conteúdo de umidade e voláteis foram calculados pela razão entre a massa perdida durante o procedimento e a massa inicial, em percentual. 


\subsubsection{Testes de cozimento}

As características de cozimento das massas alimentícias foram determinadas utilizando a metodologia descrita por AACC no $16-50$ e 16-51 (2000), onde $10 \mathrm{~g}$ de massa alimentícia foram colocados em $140 \mathrm{ml}$ de água destilada em ebulição até o ponto ótimo de cozimento. Todas as determinações foram realizadas no mínimo em duplicata.

O tempo ótimo de cozimento foi verificado comprimindo-se, entre duas placas de vidro, uma amostra da massa alimentícia retirada do cozimento a cada $15 \mathrm{~s}$, até que o centro da massa alimentícia se tornar esbranquiçada, indicando que o amido no centro da massa estava hidratado.

A determinação de absorção de água no produto cozido foi determinada a partir da diferença entre um peso fixo de massa crua (10 g) e o peso da massa após o cozimento.

Para a determinação de perda de sólidos solúveis na água de cozimento, colocou-se $5 \mathrm{ml}$ da água de cozimento em uma cápsula de alumínio (previamente seca e tarada). Em seguida, as cápsulas foram colocadas em estufa (EL 003, Odontobrás, Ribeirão Preto/SP,Brasil) a $105^{\circ} \mathrm{C}$, até se obter peso constante.

\subsubsection{Caracterização cromática pelo método CIE L*a*b*}

A análise de cor foi determinada por meio de colorímetro tristímulo (HUNTERLAB 4500L, USA), com leitura direta de refletância das coordenadas $L^{*}, a^{*}, b^{*}, H^{*}$ e C*, empregando-se a escala CIE L*a*b* (CIE, 2004) e utilizando o iluminante $\mathrm{D}_{65}$ e $10^{\circ}$. Após a calibração do equipamento com placa de cerâmica branca e preta padronizadas pelo fabricante, as massas alimentícias (crua e cozida em temperatura ambiente) foram colocadas em cápsulas de alumínio, onde foram efetuadas as determinações em triplicata.

\subsection{Avaliação sensorial}

O projeto de avaliação sensorial da aplicação do extrato de camarão na formulação de massa alimentícia foi encaminhado para o Comitê de Ética em Pesquisa com Seres Humanos da Universidade Federal de Santa Catarina (UFSC - Processo número 907, de 30 de agosto de 2010) e, com aprovação no mesmo, os testes sensoriais foram aplicados. Os provadores que participaram das análises sensoriais receberam oTermo de Consentimento Livre e Esclarecido com informações sobre a pesquisa, e assim registraram o seu esclarecimento sobre o projeto e disponibilizaram formalmente seus dados para a utilização no mesmo.

Para os testes triangulares (unilateral, $\mathrm{p}=1 / 3$ ) de diferença das massas alimentícias pigmentadas com o extrato do resíduo foram recrutados 50 julgadores não treinados, porém familiarizados com o produto Foram realizados dois grupos de testes de diferença: o primeiro, a fim de determinar se existe diferença significativa ( $p$ $<0,05)$ na coloração entre a massa alimentícia com menor concentração de extrato (formulação I - Tabela 1) e o controle (sem adição de extrato); e o segundo, para verificar se existe diferença entre a massa alimentícia com maior concentração de extrato (formulação II-Tabela 1) e o controle. O objetivo destes testes foi avaliar a diferença significativa na coloração das massas e determinar a mínima concentração perceptível, considerando que os julgadores avaliaram apenas visualmente as amostras cruas de massa alimentícia, de acordo com a forma em que os consumidores a adquirem comercialmente. 
A análise dos dados dos testes triagulares foi realizada segundo a NBR 12995 (ABNT,1993).

Para os testes de aceitabilidade e intenção de compra, foram convocados 55 julgadores não treinados, mas familiarizados com o produto. A mínima concentração de extrato carotenoídico determinada como perceptível nos testes triangulares foi utilizada na formulação das massas alimentícias para os testes de aceitabilidade e intenção de compra. Os julgadores receberam uma amostra de 2,5 g de massa alimentícia submetida à cocção de acordo com os padrões determinados nos testes de cozimento, e uma ficha de avaliação sensorial. Para a análise de aceitabilidade, foi apresentada aos julgadores uma escala hedônica de nove pontos ancorada nos seus extremos com os termos: "gostei muitíssimo" e "desgostei muitíssimo". Para o teste de intenção de compra, as opções eram "certamente compraria"e "certamente não compraria”. Assim, solicitou-se aos julgadores que indicassem o conceito que melhor avaliava o seu sentimento em relação ao produto e se incentivou que manifestassem suas observações relevantes relacionados ao produto.

\subsection{Análises microbiológicas}

As análises microbiológicas foram realizadas segundo a American Public Health Association (APHA, 2001), no Laboratório de Análises (LABCAL) daUFSC. Foram analisados os microrganismos Bacillus cereus, coliformes a $45^{\circ} \mathrm{C}$, Estafilococos coagulase positiva e Salmonella sp da massa alimentícia crua na formulação II, a qual foi utilizada para os testes de aceitabilidade e intenção de compra.

\subsection{Análise estatística}

Os resultados foram submetidos à análise de variância (ANOVA), seguido do teste de Tukey ao nível de 5\% de significância, usando o software Assistat 7.6 (SILVA, 2011).

\section{RESULTADOS E DISCUSSÃO}

\subsection{Análises físico-químicas}

\subsubsection{Teor de umidade e voláteis e testes de cozimento}

Os teores de umidade e voláteis, tempo de cozimento e determinação de absorção de água e perda de sólidos solúveis na água de cozimento determinados para as massas alimentícias frescas estão descritos na Tabela 2.

Os resultados mostram que os teores de umidade para a amostra controle e as formulações com a adição do extrato carotenoídico não diferem significativamente, indicando que não há interferência da adição do extrato no teor de umidade e voláteis das massas alimentícias. A umidade encontrada nas formulações está dentro do padrão estipulado pela legislação brasileira.

O tempo de cozimento não diferiu significativamente entre as formulações estudadas, sendo que a amostra controle apresentou o maior tempo de cozimento $(328 \pm 6$ s) e a formulação II o menor tempo (327 \pm 3 s). Chang e Flores (2004) encontraram valor semelhante (360 s) para massa alimentícia fresca elaborada apenas com água e farinha de trigo. 
Os resultados demonstram uma maior absorção de água das massas proporcional com a diminuição do uso do extrato natural nas formulações (Tabela 2). O aumento de peso, segundo Ormenese (2001) e Mariusso (2008), está diretamente ligado ao conteúdo e qualidade de proteínas, que, no processo de mistura, hidratam e absorvem água, aumentando o volume e consequentemente o peso. A formulação II apresentou a menor absorção de água durante o cozimento $(106 \% \pm 5)$. Mariusso (2008) encontrou valores de 76,66\% na determinação de absorção de água de massas alimentícias frescas elaboradas com farinha de trigo especial, ovo e água. Entretanto, Boroski et al. (2011) reporta o valor de 181,07\% em massa alimentícia fresca (farinha de trigo, semolina, água). Estes valores demonstram que a absorção de água durante o cozimento depende diretamente dos ingredientes e da porcentagem deles nas formulações.

A formulação I apresentou a menor porcentagem de perda de sólidos solúveis na água de cozimento $(1,19 \% \pm 0,08)$. Contudo, as outras formulações apresentaram valores diferentes estatisticamente da formulação I, sendo para formulação II $2,4 \% \pm 0,2$ e para a amostra controle $2,49 \% \pm 0,06$, estas iguais estatisticamente. As perdas de sólidos solúveis de até 6\% são características de massas de trigo de boa qualidade, até $8 \%$ para massas de trigo de média qualidade e valores iguais ou superiores a $10 \%$ são características de massas de baixa qualidade (HUMMEL, 1996), indicando que as massas elaboradas com ERC 10\% possuem uma boa qualidade perante o padrão analisado.

Tabela 2: Resultados de umidade, tempo de cozimento e sólidos perdidos na água de cozimento das respectivas formulações de massa alimentícia fresca

\begin{tabular}{l|c|c|c|c}
\multicolumn{1}{c|}{ Formulação } & Umidade (\%) & $\begin{array}{c}\text { Tempo de } \\
\text { cozimento (s) }\end{array}$ & $\begin{array}{c}\text { Absorção de } \\
\text { água (\%) }\end{array}$ & $\begin{array}{c}\text { Sólidos solúveis } \\
(\%)^{(1)}\end{array}$ \\
\hline Controle & $28,5^{\mathrm{a}} \pm 0,5$ & $328^{\mathrm{a}} \pm 6$ & $114^{\mathrm{a}} \pm 7$ & $2,49^{\mathrm{a}} \pm 0,06$ \\
\hline Formulação I(2) & $28,96^{\mathrm{a}} \pm 0,08$ & $319^{\mathrm{a}} \pm 2$ & $110^{\mathrm{a}} \pm 2$ & $1,19^{\mathrm{b}} \pm 0,08$ \\
\hline Formulação II (2) & $29,1^{\mathrm{a}} \pm 0,5$ & $327^{\mathrm{a}} \pm 3$ & $106^{\mathrm{a}} \pm 5$ & $2,4^{\mathrm{a}} \pm 0,2$ \\
\hline
\end{tabular}

${ }^{(1)}$ Mesmas letras sobrescritas em mesma coluna indicam igualdade significativa $(p<0,05)$.

(2) Formulação I (3,6ml água, 1,4ml ERC10\%); Formulação II (5ml ERC10\%).

Fonte: Dos autores (2016)

\subsubsection{Caracterização cromática}

Os resultados da análise cromática obtidos pelo sistema CIE L*a*b* são representados por caracteres onde $\mathrm{L}^{*}$ significa luminosidade em uma escala de 0 (totalmente preto) a 100 (totalmente branco), $\mathrm{a}^{*}$ define o eixo que varia entre o verde evermelho $\mathrm{eb}^{*}$ expressa o eixo que varia entre o azul e amarelo (FARKAS, 2003; KEEY, 2004; RIBEIRO, 2006). O ângulo de tonalidade, hue $\left(\mathrm{H}^{*}\right)$ é medida derivada de $\mathrm{a}^{*} \mathrm{e}$ assume valorzero para a coloração vermelha, $90^{\circ}$ para amarela, $180^{\circ}$ para verde e $270^{\circ}$ para a azul. O índice de saturação croma $\left(\mathrm{C}^{*}\right)$, calculado a partir da derivada de $b^{*}$, define a intensidade da cor, sendo que valores próximos de zero 
representam cores neutras e valores próximos de 60 significam cores vivas (HUTCHINGS, 2002; MENDONÇA et al., 2003; RIBEIRO, 2006).

Segundo a análise cromática, os resultados positivos de $a^{*}$ e b* (Tabela 3) demonstram que todas as massas alimentícias analisadas se situam nos eixos, respectivamente, das coresvermelha e amarela.O fato de $b^{*}$ apresentar valores maiores que $\mathrm{a}^{*}$ demonstra uma influência maior $\mathrm{da}$ cor amarela, cor característica de massas alimentícias, devido principalmente à adição de ovos inteiros na formulação e a umidificação da farinha de trigo com posterior amassamento.

A massa alimentícia cozida com formulação II apresentou o maior valor de $b^{*}(31,9 \pm 0,3$ - Tabela 3) e o menor valor deste parâmetro foi encontrado na massa crua na amostra com formulação controle $(20,2 \pm 0,4)$. Chang e Flores (2004) relatam um valor de b* igual a 9,86 em massa alimentícia formulada apenas com água e farinha de trigo, de forma que estes valores comprovam a influência do ovo e principalmente da adição do extrato carotenoídico natural na formulação de massa alimentícia fresca, sendo que a presença destes eleva a coloração amarela do produto, além de aumentar sua aceitabilidade e incrementar o valor nutricional da massa alimentícia.

Os valores de a* são crescentes e diferem significativamente entre a amostra controle, formulação I e formulação II, tanto para massa crua quanto cozida. Isto significa que há um aumento no teor de pigmentação vermelha nas massas, sendo que a formulação II de massa alimentícia cozida apresentou o maior teor de pigmentação vermelha $(10,0 \pm 0,2)$ e a amostra controle de massa crua o menor $(1,56 \pm 0,07)$ (Tabela 3). Outro fator que justifica o aumento da coloração vermelha é a diferença significativa entre os valores de $\mathrm{H}^{*}$ (Tabela 3 ), que, quanto mais próximo de zero, mais vermelha a coloração. O maior teor de pigmentação vermelha nas massas de formulação II em comparação com as amostras controle é justificado pelo fato do extrato carotenoídico conter principalmente a astaxantina, carotenoide de coloração vermelha. Os valores apresentados comprovam que o extrato natural utilizado neste estudo possui a capacidade de pigmentar massa alimentícia fresca.

Os valores do índice de saturação croma $\left(C^{*}\right)$, que define a intensidade da cor, foram maiores nas formulações que possuíam a maior quantidade de extrato carotenoídico (Tabela 3), tanto para massa crua quanto para a cozida. Este fato indica que, além de pigmentar a massa alimentícia, o extrato carotenoídico possui a capacidade de aumentar a intensidade da sua cor. 
Tabela 3: Caracterização cromática da amostra controle e das duas formulações de massa alimentícia fresca com adição de ERC 10\% pelo método CIE L*a*b*

\begin{tabular}{|c|c|c|c|c|c|c|}
\hline \multirow[b]{2}{*}{$\begin{array}{c}\text { Parâmetros } \\
\text { de cor }\end{array}$} & \multicolumn{3}{|c|}{ Massa alimentícia crua ${ }^{(1)}$} & \multicolumn{3}{|c|}{ Massa alimentícia cozida ${ }^{(1)}$} \\
\hline & Controle & $\begin{array}{l}\text { Formulação } \\
\qquad \text { I(2) }^{(2)}\end{array}$ & $\begin{array}{c}\text { Formulação } \\
\qquad \text { II }^{(2)}\end{array}$ & Controle & $\begin{array}{l}\text { Formulação } \\
\qquad \text { I (2) }^{\text {(2) }}\end{array}$ & $\begin{array}{c}\text { Formulação } \\
\qquad I^{(2)}\end{array}$ \\
\hline $\mathbf{L}^{*}$ & $76,0^{\mathrm{a}} \pm 0,5$ & $75,3^{\mathrm{a}} \pm 0,8$ & $72,0^{\mathrm{b}} \pm 0,5$ & $68,6^{c} \pm 0,3$ & $65,5^{\mathrm{d}} \pm 0,3$ & $61,4^{\mathrm{e}} \pm 0,1$ \\
\hline$a^{*}$ & $\begin{array}{c}1,56^{\mathrm{f}} \pm \\
0,07\end{array}$ & $3,06^{\mathrm{e}} \pm 0,05$ & $4,9^{c} \pm 0,2$ & $\begin{array}{c}4,30^{\mathrm{d}} \pm \\
0,04\end{array}$ & $7,19^{\mathrm{b}} \pm 0,04$ & $10,0^{\mathrm{a}} \pm 0,2$ \\
\hline $\mathbf{b}^{*}$ & $20,2^{f} \pm 0,4$ & $22,8^{\mathrm{e}} \pm 0,4$ & $23,9^{d} \pm 0,6$ & $25,1^{\mathrm{c}} \pm 0,2$ & $30,7^{\mathrm{b}} \pm 0,1$ & $31,9^{\mathrm{a}} \pm 0,3$ \\
\hline$C^{*}$ & $20,3^{f} \pm 0,4$ & $23,0^{\mathrm{e}} \pm 0,4$ & $24,4^{\mathrm{d}} \pm 0,6$ & $25,4^{\mathrm{c}} \pm 0,2$ & $31,5^{\mathrm{b}} \pm 0,1$ & $33,4^{\mathrm{a}} \pm 0,4$ \\
\hline $\mathbf{H}^{*}$ & $85,6^{a} \pm 0,2$ & $82,4^{\mathrm{b}} \pm 0,1$ & $78,5^{\mathrm{d}} \pm 0,2$ & $\begin{array}{c}80,27^{\mathrm{c}} \pm \\
0,04\end{array}$ & $76,81^{\mathrm{e}} \pm 0,03$ & $72,5^{f} \pm 0,1$ \\
\hline
\end{tabular}

${ }^{(1)}$ Mesmas letras em mesma linha indicam igualdade significativa $(p<0,05)$.

(2)Formulação I (3,6ml água, 1,4ml ERC 10\%); Formulação II (5ml ERC10\%).

Fonte: Dos autores (2016)

A Figura 1 mostra os "ninhos" da amostra controle, formulação I e formulação II. Um aumento suave da coloração avermelhada nas massas pode ser visualizado da Figura 1 (a) para a Figura 1 (c).

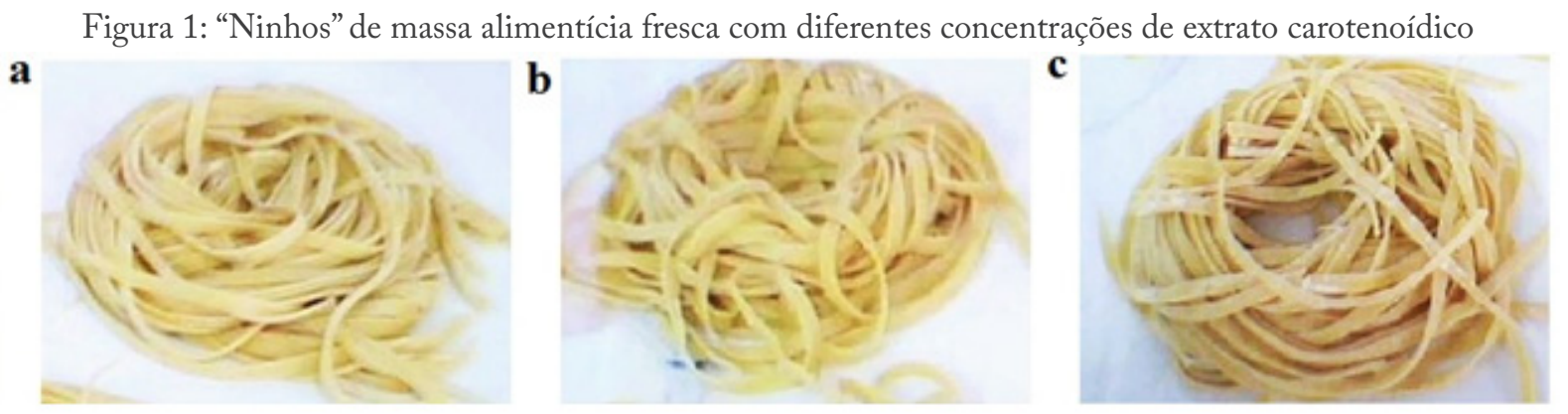

Amostra controle (a); Formulação I (b); e Formulação II (c).

Fonte: Dos autores (2015)

\subsection{Avaliação sensorial}

Análises microbiológicas foram realizadas na massa alimentícia formulação II, a fim de comprovar a inocuidade microbiológica da amostra submetida à análise sensorial. Os resultados estão descritos na Tabela 4. Segundo a Resolução da Diretoria Colegiada RDC n
12, de 02 de janeiro de 2001 (ANVISA/MS), a amostra satisfaz os padrões de qualidade quanto aos parâmetros analisados. Os resultados das análises microbiológicas indicam que a qualidade microbiológica da massa alimentícia crua está dentro dos padrões estabelecidos pela legislação brasileira. Assim, os testes sensoriais foram conduzidos a fim de determinar a 
mínima concentração perceptível visualmente ao consumidor, seguidos dos testes de aceitação global e intenção de compra.

No teste triangular, 28 das 50 pessoas que avaliaram o produto indicaram corretamente a amostra diferente entre a massa alimentícia de formulação I em comparação com a amostra controle, enquanto, ao se comparar a amostra controle com a formulação II, 47 das 50 pessoas avaliadas identificaram de forma correta a amostra diferente. Nos dois testes realizados, as amostras diferem significativamente em coloração ao nível de significância de $\alpha=0,1 \%$. Estes resultados demonstram que a adição do extrato natural na formulação, mesmo em menor concentração, foi perceptível visualmente no produto acabado cru, quando comparado com a massa alimentícia controle (sem adição do extrato).

A partir dos resultados obtidos nos testes triangulares, optou-se usar as massas alimentícias com formulação II para a análise de aceitação global e intenção de compra, considerando os comentários dos julgadores quanto à dificuldade de identificar a amostra diferente quando o teste triangular foi realizado com as massas de formulação I, aliado ao fato de a intensidade de coloração ser considerado um fator decisivo para a compra de massas alimentícias pelos consumidores.
O teste de aceitação global para a massa alimentícia de formulação II indicou o valor de 6,5 como índice médio de aceitabilidade do produto. A média encontrada situou-se entre os conceitos "gostei ligeiramente" e "gostei regularmente". Ormenese et al. (2004) encontrou resultados semelhantes de 6,9 a 7,3 para o índice de aceitação global de massas alimentícias elaboradas com farinha de trigo, água e diferentes quantidade de ovos. Já para a avaliação de intenção de compra, 81,82\% dos julgadores declararam que comprariam o produto analisado.

\section{Apesar da média de aceitação global situar-se em uma pontuação intermediária, o número de julgadores que comprariam o produto foi elevado.}

Provavelmente isso se deve ao fato de que este produto é consumido com algum tipo de acompanhamento, como molhos, sendo que o produto sem a adição do acompanhamento pode ter causado estranheza aos avaliadores. Apesar disso, o número de julgadores que comprariam o produto foi considerado alto, já que mais da metade dos avaliadores comprariam o produto. Lemes et al. (2012) obtiveram resultados negativos de intenção de compra em massa alimentícia com adição de 5 e 10\% de biomassa de Spirulina platensis quando comparada com a amostras padrão.

Tabela 4: Resultados das análises microbiológicas realizadas na formulação II de massa alimentícia crua

\begin{tabular}{l|c}
\multicolumn{1}{c|}{ Microrganismos } & Resultados \\
\hline Bacillus cereus & $<1,0 \times 10^{2} \mathrm{UFC} / \mathrm{g}$ \\
\hline Coliformes a $45^{\circ} \mathrm{C}$ & $<3 \mathrm{NMP} / \mathrm{g}$ \\
\hline Estafilococos coagulase positiva & $<1,0 \times 10^{1} \mathrm{UFC} / \mathrm{g}$ \\
\hline Salmonella sp. & ausência em $25 \mathrm{~g}$ \\
\hline
\end{tabular}

Fonte: Dos autores (2016) 


\section{CONCLUSÕES}

A adição do extrato carotenoídico proveniente do resíduo de processamento de camarão rosa (P.brasiliensise P.paulensis) se mostrou eficiente na coloração de massa alimentícia fresca quando adicionado junto à formulação, promovendo diferenças significativas nos parâmetros físicos referentes às cores amarela e vermelha, e sendo perceptível sensorialmente aos consumidores.

Ainda, a adição de extrato não afetou os parâmetros (umidade e voláteis, tempo ótimo de cozimento, absorção de água e perda de sólidos) avaliados para atestar a qualidade da massa alimentícia, não promoveu alterações microbiológicas no produto, mantendo-o dentro dos padrões estabelecidos pela legislação brasileira. Por fim, a massa alimentícia fresca com adição do extrato carotenoídico obteve bons índices sensoriais de aceitação global e intenção de compra.

\section{AGRADECIMENTOS}

Os autores agradecem à Fundação de Amparo à Pesquisa e Inovação do Estado de Santa Catarina (FAPESC) e ao Conselho Nacional de Desenvolvimento Científico e Tecnológico (CNPq) pelo suporte financeiro. 


\section{USE OF NATURAL CAROTENOID- ENRICHED EXTRACT IN THE FORMULATION OF FRESH PASTA}

\begin{abstract}
Pastas are pigmented mainly with synthetic $\beta-c a-$ rotene. The addition of pigments stemmed from food industry waste recovery can add value to the product and reduceproblems with waste disposal. Thus, the aim of this study was to determine the physical-chemical properties and evaluate the acceptability of fresh pasta with the addition of different concentrations of carotenoid-enriched extract from pink shrimp (Penaeus brasiliensis and Penaeus paulensis) processing waste. Three differentfresh pasta formulations wereprepared, a sample control and two addition of carotenoid-enriched extract $(0.9 \%$ and $3.1 \%$ of $10 \%$ extract), from pinkshrimp processing waste. The extractwas added to formulations intended to enhance the color of the pasta. Physical-chemical analysis (moisture volatile, cooking and colortests) wereperformed in order to evaluate the quality of the prepared pasta. Formulations containing addition of extract differ significantly in relation to the color of the sample. Formulation II (3.1\% of natural extract 10\%) promoted the best sensory results, with an index of 6.5 of global acceptability and purchase intent of $81.82 \%$.
\end{abstract}

Keywords: Shrimp waste. Food dye. Purchase intention. Global acceptability.

\section{REFERÊNCIAS}

AMERICAN ASSOCIATION OF CEREAL CHEMISTS (AACC). Official methods of the American Association of Cereal Chemists. St. Paul, MN, USA, 2000.

AMERICAN PUBLIC HEALTH ASSOCIATION (APHA). Compendium of methods of the microbiological examination of foods. 4. ed. Washington: APHA, 2001.

ASSOCIAÇÃO BRASILEIRA DAS INDÚSTRIAS DE BISCOITOS, MASSAS ALIMENTÍCIAS E PÃES BOLOS IND. (ABIMAPI). Estatísticas de massas alimentícias. Disponível em: <www.abimapi.com.br>. Acesso em: 16 de mar. 2016.

\section{ASSOCIAÇÃO BRASILEIRA DE NORMAS} TÉCNICAS (ABNT). NBR 12995: teste triangular em análise sensorial de alimentos e bebidas. Rio de Janeiro, 1993.

BOROSKI, M. et al. Enhancement of pasta antioxidant activity with oregano and carrot leaf. Food Chemistry, v. 125, n. 2, p. 696 - 700, 2011.

BRASIL. Agência Nacional de Vigilância Sanitária. Resolução no 93, de 31 de outubro de 2000. Dispõe sobre o Regulamento técnico para fixação de identidade e qualidade de massa alimentícia ou macarrão. Diário Oficial [da] República Federativa do Brasil, Brasília, 26 out. 2000.

Agência Nacional de Vigilância Sanitária. Resolução no 12, de 2 de janeiro de 2001. Aprova o Regulamento Técnico Sobre Padrões Microbiológicos para Alimentos. Diário Oficial [da] República Federativa do Brasil, Brasília, 20 dez. 2000. 
CHANG, Y. K.; FLORES, H. E. M. Qualidade tecnológica de massas alimentícias frescas elaboradas de semolina de trigo durum (T. durum L.) e farinha de trigo (T. aestivum L.). Ciência e Tecnologia de Alimentos, v. 24, n. 4, p. 487-493, 2004.

CHOUBERT, G.; LUQUET, P. Utilization of shrimp meal for rainbow trout (Salmo Gairdneri Rich.) pigmentation: influence of fat content of the diet. Aquaculture, v. 32, p. 19-26, 1983.

\section{CIE. Colorimetry. CIE 15:2004. CIE, 2004.}

FARKAS, C. Curso sobre aplicação em colorimetria e aparência na indústria. Tecnocor Serviços, São Paulo, p. 140, 2003.

\section{INSTITUTO DE TEDNOLOGIA DE} PERNANBUCO (ITEP). Macarrão. Recife: ITEP, 1985.

HU, Z-C. et al. pH control strategy in astaxanthin fermentation bioprocess by Xanthophyllomyces dendrorhous. Enzyme and Microbial Technology, v. 39, p. 586-590, 2006.

HUMMEL, C. Macaroni Products: manufacture, processing and packing. 2. ed. London: Food Trade Press, 1996.

HUTCHINGS, J. B. The perception and sensory assessment of colour. In: Macdougall, D. B. (editor). Colour in food. England: Woodhead Publishing Limited, 2002.

INSTITUTO ADOLFO LUTZ (IAL). Métodos físico-químicos para análise de alimentos. São Paulo: Instituto Adolfo Lutz, 2008. 1020 p.

KEEY, R. B. Colour development on drying. In: 14th International Drying Symposium, 2004. São Paulo.

LAMBERSTEN, G.; BRAEKKAN, O. R. Method of analysis of astaxanthin and its occurrence in some marine products. Journal of Science and Food Agriculture, v. 22, p. 99 - 101, 1971.

LEMES, A.C. et al. Fresh Pasta Production Enriched with Spirulina platensis Biomass. Brazilian Archives of Biology and Technology, v. 55, n. 5, p. 741-750.
MARIUSSO, A. C. B. Estudo do enriquecimento de massas alimentícias com subprodutos agroindustriais visando o melhoramento funcional e tecnológico de massas frescas. 2008. Tese -

Universidade Estadual de Campinas, São Paulo. 2008.

MENDONÇA, K. et al. A. Concentração de etileno e tempo de exposição para desverdecimento de limão 'siciliano'. Brazilian Journal of Food Technology, v. 6, n. 2, p. $179-183,2003$.

MEZZOMO, N. et al. Pink shrimp (P. brasiliensis and P. paulensis) residue: Influence of extraction method on carotenoid concentration. Talanta, v. 85, p. 1383-1391, 2011.

ORMENESE, R. C. S. C. et al. Massas alimentícias não convencionais à base de arroz - perfil sensorial e aceitação pelo consumidor. Brazilian Journal of Food Technology, v. 4, p. 67-74, 2001.

; FARIA, E. V. Influência do uso de ovo líquido pasteurizado e ovo desidratado nas características da massa alimentícia. Ciência e Tecnologia dos Alimentos, v. 24, n. 2, p. 255-260, 2004.

RIBEIRO, D. M. Evolução das propriedades físicas, reológicas e químicas durante o amadurecimento da banana “prata-anã". 2006. Tese - Universidade Federal de Viçosa, Minas Gerais. 2006.

SILVA, F. A. Estudo da aplicação de energia de micro-ondas na secagem da noz macadâmia (Madamia integrifolia Maiden \& Betche). 2005. Tese - Universidade Estadual de Campinas, São Paulo. 2005.

SILVA, F. DE A. S. Assistat. Versão 7.6 beta. 2011. Disponível em: <http://www.assistat.com/indexp. html $>$. Acesso em: 25 nov. 2015.

SIMPSON, B. K.; HAARD, N. F. The use of proteolytic enzymes to extract carotenoproteins from shrimp wastes. Journal of Applied Biochemistry, v. 7, p. 212-222, 1985.

Data de recebimento: $17 / 11 / 2014$

Data de aprovação: 29/07/2016 


\section{SOBRE OS AUTORES}

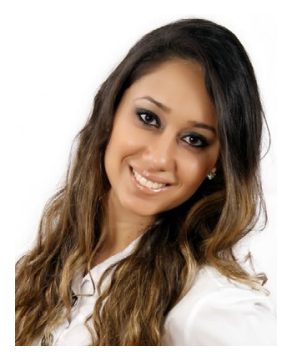

Sara Albino Antunes Valcareggi

Graduada em Engenharia de Alimentos pela Universidade Estadual de Santa Catarina - UDESC (2010) e Mestre na mesma área pela Universidade Federal de Santa Catarina (2013). Atualmente é doutoranda em Engenharia de Alimentos na UFSC com o projeto de pesquisa Extração e caracterização de compostos obtidos a partir do resíduo do processamento de siri-azul (Callinectes sapidus) e ministra aulas no curso de Aprendizagem Industrial de Operador de Alimentos no Serviço Nacional de Aprendizagem Industrial de Santa Catarina (SENAI). Atua na área de tecnologia supercrítica e encapsulamento de compostos bioativos no Laboratório deTermodinâmicae ExtraçãoSupercrítica (LATESC) no Departamento de engenharia Química e engenharia de Alimentos da UFSC.

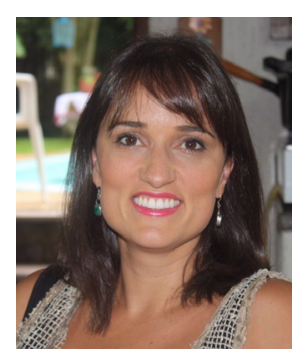

\section{Natália Mezzomo}

Graduada em Engenharia de Alimentos pelaUniversidade de Passo Fundo (2006), com mestrado (2008) e doutorado (2012) em Engenharia de Alimentos pela Universidade Federal de Santa Catarina (2008). Atua principalmente com Tecnologia Supercrítica, aplicada a extração e encapsulamento de compostos bioativos, mas também com modelagem, determinação de parâmetros de processo e avaliação de atividades biológicas e tecnológicas de extratos naturais. Atualmente é estagiária de Pós-doutorado do Departamento de Engenharia Química e Engenharia de Alimentos da UFSC, atuando na área de precipitação e encapsulamento de compostos bioativos.

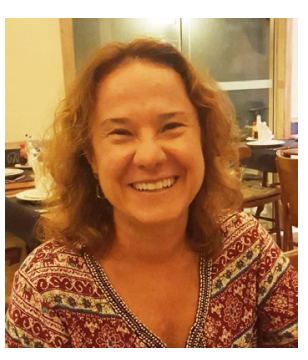

Sandra Regina Salvador Ferreira

Graduada em Engenharia de AlimentospelaUFSC(1987), mestrado em Engenharia de Alimentos pelaUniversidade Estadual de Campinas - UNICAMP (1991) e doutorado em Engenharia de Alimentos pela UNICAMP (1996). Ingressou como professora da Universidade Federal de Santa Catarina (UFSC) em 1996. Tem experiência na área de Ciência e Tecnologia de Alimentos, comênfase em Engenharia deAlimentos, atuando principalmente nos seguintes temas: extração supercrítica, dióxido de carbono, óleos essenciais e atividades biológicas. Publicou vários artigos em revistas especializadas e participa de inúmeros projetos de pesquisa e de cooperação. Dentre as atividades administrativas destaca-se a atuação como Diretora do Departamento de Integração Acadêmica e Profissional da Pró-Reitoria de Ensino de Graduação da UFSC (3 anos), como Coordenadora de Curso de Graduação (4,5 anos) e como vice-coordenadora de Pós-Graduação (4,5 anos). Atualmente desempenha a função de subchefe do Departamento de Engenharia Química e Engenharia de Alimentos da UFSC.

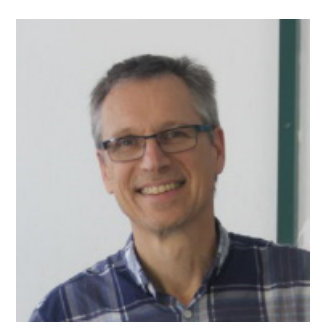

\section{Haiko Hense}

Graduado em Engenharia Química pela Universidade Federal do Paraná (1981), mestrado em Engenharia de Alimentos pelaUniversidade Estadual de Campinas (1990) e doutorado em Engenharia de Processos pela Universidade Técnica de Hamburgo - Harburg - Technische Uni. Hamburg-Harburg (1997). Atualmente é professor titular da Universidade Federal de Santa Catarina. 
Tem experiência na área de Ciência e Tecnologia de Alimentos, com ênfase em Operações de Separação e Mistura, atuando principalmente nos seguintes temas: supercritical fluid extraction (extração supercrítica) de antioxidantes naturais, condimentos,óleos essenciais e congelamento de alimentos.

\section{***}

